\title{
Influence of low-specific speed pump modifications on stability of Y-Q curve
}

\author{
Roman Klas ${ }^{1, a}$, František Pochylý ${ }^{1}$ and Pavel Rudolf ${ }^{1}$ \\ ${ }^{1}$ Brno University of Technology, Faculty of Mechanical Engineering, Victor Kaplan Department of Fluids Engineering, \\ Technická 2, 61669 Brno, Czech Republic
}

\begin{abstract}
Contribution is focused on modification of low-specific speed pump impellers with respect to stability of their Y-Q curves (i.e. head curves). The design modifications are driven by analysis of the dissipated power. First, dissipated power is evaluated by CFD software in individual working parts of the pump and then its dependence on flow rate is investigated. Pressure fields within the pump are also carefully examined. Special attention is paid to impellers and configuration of the blade channels and recirculating channels. Results point to significant influence of the proper inflow to recirculating channels and also to role of the volute, which is more pronounced than in conventional impellers. All integral characteristics from CFD simulations are verified experimentally.
\end{abstract}

\section{Introduction}

The low specific speed centrifugal pumps are known for their low hydraulic efficiency. The reason is usually ascribed to secondary flow in blade channels of impellers, where so called local eddy develops. This phenomenon causes increased losses due to recirculation and also higher streamline curvature at the impeller outlet, resulting in a significant decrease of the angle at which the liquid leaves the impeller (viewed in relative rotating space). This deviation from the blade outlet angle poses reduction of attainable delivery head or specific energy $[1,2]$.

Operating characteristics of the centrifugal pumps may show signs of instability, which may significantly affect the possibilities of their use. The specific energy curves used to be fundamental from this point of view. The instability can be detected or the problems with the pulsation of the static pressure and noise of the machine can be predicted on the base of these curves.

Above mentioned problems are often solved issue and it is therefore very important to identify the main causes of the instability. Their design of course varies according to the operating parameters of each pump. The main attention in this paper is focused on the low specific speed centrifugal pump. Investigated pump will be equipped with a conventional impeller with thin blades and a new impeller with thick trailing edges. As a basic tool for the analysis CFD simulations will be employed. Wherever it is possible the results from the CFD analysis are compared to the data obtained from the experiment [3].

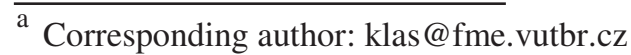

\section{Main parameters and computational mode of CFD simulations}

To better define the scope, which will be solved in the analysis, we first define specific speed, which is determined by equation (1):

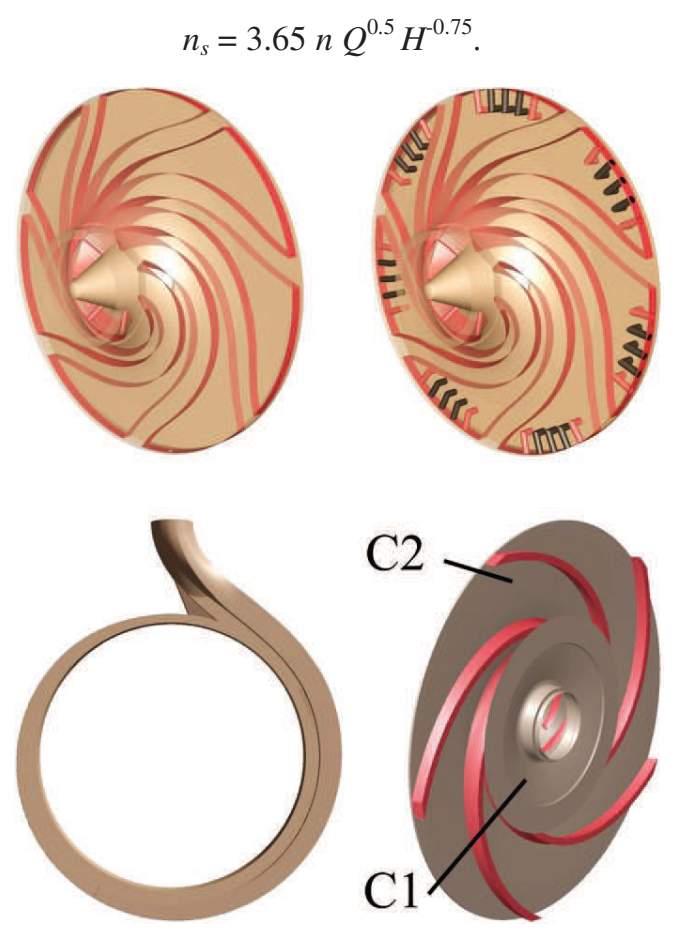

Figure 1. Impellers with thick trailing edges and with / without recirculation channels, spiral case and conventional impeller. 
Current specific speed is in Table 1. The pump is designed without the guide vanes and is equipped with impellers according to Figure 1 and Figure 2. The impellers are designed for the same operating parameters and main dimensions are summarized in Table 1.
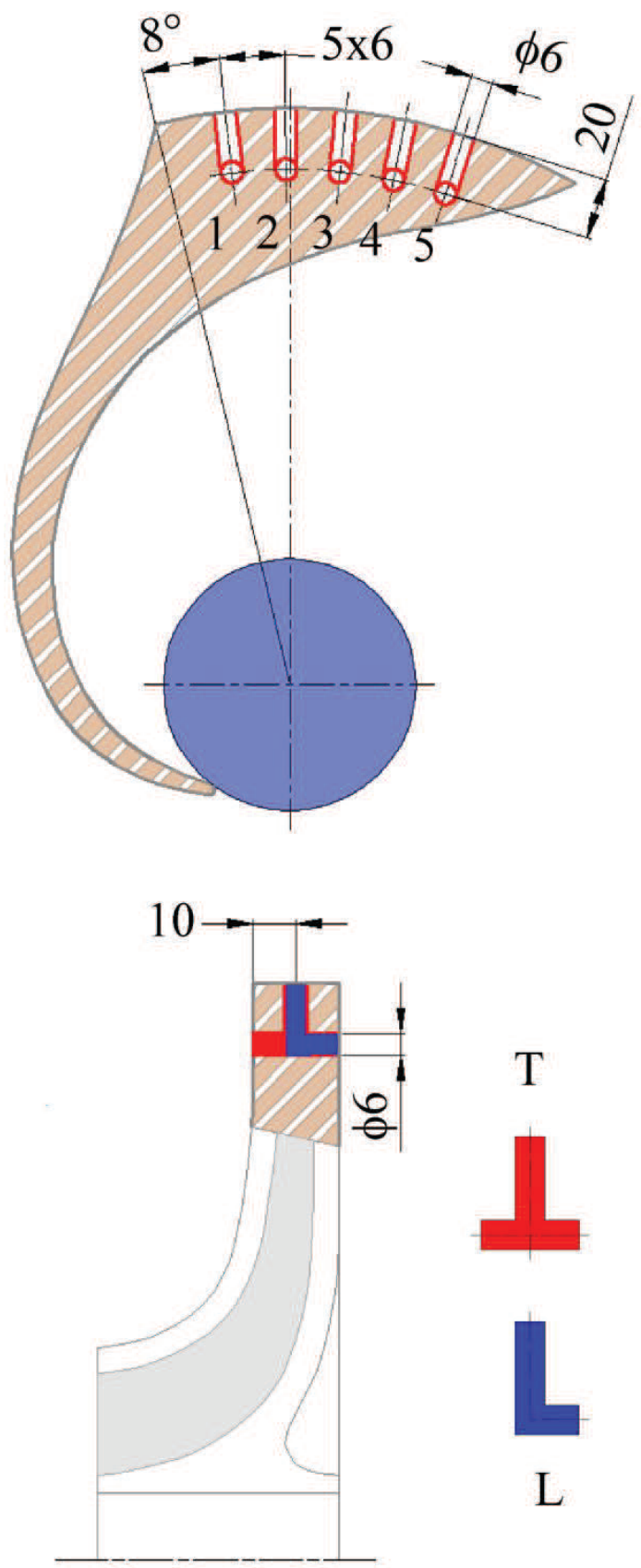

Figure 2. Blade-to-blade view and meridional section of the pump.

As can be seen from Figure 1 and Figure 2 different concepts of impellers will be compared in other part of this paper. The basic instrument for stability analysis is represented by the CFD simulations carried out in the solver ANSYS Fluent 14.5.7. Preprocessor GAMBIT 2.4.6 was used to create computational meshes. Detailed information can be found in Table 1.
Table 1. Basic design parameters and description of numerical model.

\begin{tabular}{|c|c|c|c|c|}
\hline & $\mathrm{C}$ & $\mathrm{E}$ & $\mathrm{T}$ & $\mathrm{L}$ \\
\hline $\mathrm{C}, \mathrm{C} 1, \mathrm{C} 2$ & \multicolumn{4}{|c|}{ Conventional impeller } \\
\hline $\mathrm{E}$ & \multicolumn{4}{|c|}{$\begin{array}{l}\text { Impeller with thick trailing } \\
\text { edges }\end{array}$} \\
\hline $\mathrm{T}, \mathrm{L}$ & \multicolumn{4}{|c|}{$\begin{array}{l}\text { Impeller with thick trailing } \\
\text { edges and recirculation channel } \\
\mathrm{T}, \mathrm{L} \text { - shape of the recirculation } \\
\text { channels }\end{array}$} \\
\hline z - number of blades & 5 & & \multicolumn{2}{|c|}{7} \\
\hline $\begin{array}{l}\beta_{2}\left({ }^{\circ}\right) \text { - average value of } \\
\text { outlet blade angle }\end{array}$ & 32 & & \multicolumn{2}{|c|}{63} \\
\hline $\begin{array}{l}\mathrm{D}_{2}(\mathrm{~m}) \text { - impeller } \\
\text { diameter }\end{array}$ & \multicolumn{4}{|c|}{0.320} \\
\hline $\mathrm{Q}\left(1 \mathrm{~s}^{-1}\right)$ - flow rate & \multicolumn{4}{|c|}{6.94} \\
\hline $\begin{array}{l}\mathrm{Y}\left(\mathrm{J} \mathrm{kg}^{-1}\right)-\text { specific } \\
\text { energy }\end{array}$ & \multicolumn{4}{|c|}{314} \\
\hline $\begin{array}{l}\mathrm{n}\left(1 \mathrm{~s}^{-1}\right) \text { - rotational } \\
\text { speed }\end{array}$ & \multicolumn{4}{|c|}{24.167} \\
\hline $\begin{array}{l}\mathrm{n}_{\mathrm{s}}\left(1 \mathrm{~min}^{-1}\right)-\text { specific } \\
\text { speed }\end{array}$ & \multicolumn{4}{|c|}{33} \\
\hline $\begin{array}{l}\text { Number of computational } \\
\text { cells }\end{array}$ & \multicolumn{4}{|c|}{$12-13$ milions } \\
\hline $\begin{array}{l}\text { Turbulence model } \\
\text { and near wall modeling }\end{array}$ & \multicolumn{4}{|c|}{$\begin{array}{l}\text { realizable } \mathrm{k}-\varepsilon \\
\text { non equilibrium wall function }\end{array}$} \\
\hline Boundary conditions & \multicolumn{4}{|c|}{$\begin{array}{l}\text { Inlet: velocity inlet } \\
\text { Outlet: pressure outlet }\end{array}$} \\
\hline Calculation mode & \multicolumn{4}{|c|}{$\begin{array}{l}\text { unsteady, sliding mesh } \\
\text { incompressible flow }\end{array}$} \\
\hline
\end{tabular}

\section{Dissipation power}

With regard to other presented characteristics it is necessary to define the condition of the stability in the way, that enables the basic consideration of the stability or instability of the specific energy characteristics. Entirely general condition [4] is given in the form (2):

$$
\frac{\partial Y}{\partial Q}<0
$$

However, it is preferable to use a criterion defined on the basis of dissipation power $2 \mathrm{D}_{\mathrm{H}}$ (hydraulic losses) specified by equation (3). More detailed information can be found in [5].

$$
\frac{\partial^{2} 2 D_{H}}{\partial Q^{2}}>0 \wedge \frac{\partial 2 D_{H}}{\partial Q}<0
$$


The advantage of this definition of specific energy curves stability is the ability to assess the impact of various parts of the centrifugal pump on the overall instability. But evaluation of dissipation power is rather problematic issue. Dissipation function (4) is a convenient tool to solve this problem:

$$
2 D_{H}=2 \eta \iiint_{V} v_{i j} v_{i j} \mathrm{dV} .
$$

However, in this case problems with the exact determination of the strain rate tensor $v_{i j}$ by the CFD analysis arise. Magnitude of its components depends on the selected computing mode (e.g. turbulence model) and does not reflect reality. Due to problems with the exact expression of the strain rate tensor in CFD simulations, the balance of the total input and output powers were finally utilized (5). A general problem that cannot be removed is the fact that close to the shut-off point [6], where the criterion (3) is valid, CFD simulations cannot provide reliable data.

$$
2 D_{H}=\sum_{i=1}^{m} P_{\text {in } i}-\sum_{j=1}^{n} P_{\text {out } j}
$$

\section{Main characteristics}

The characteristics of specific energy, hydraulic efficiency and power were used to verify the reliability of the CFD simulations results. First, characteristics of specific energy (Figure 3), which compare the results of experiments and numerical simulations will be presented.

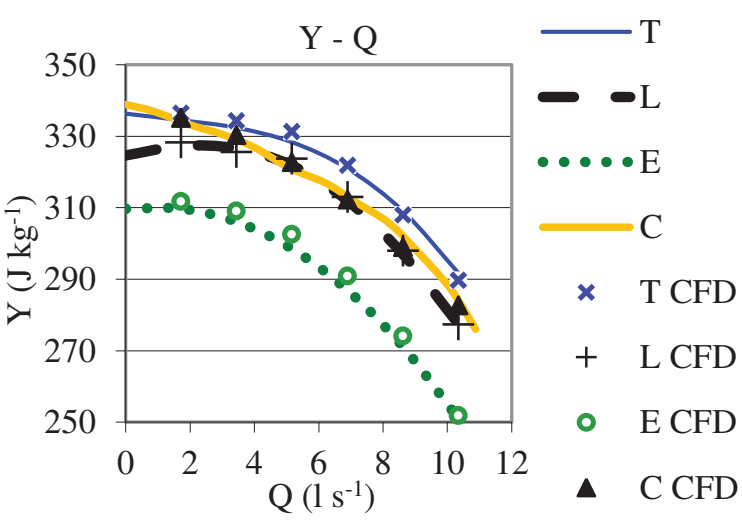

Figure 3. The specific energy curves obtained from experimental testing and from CFD simulations.

It is obvious that the most stable is the specific energy curve of the conventional impeller. Also, we can observe that the L-shaped recirculation channels negatively affect the stability. The curve of specific energy is slightly unstable close to the shut-off point. In contrast, the Tshaped recirculation channels can improve stability of impellers with thick trailing edges. Most interesting for further analysis will be the power curves in Figure 4 which provide a good idea of dissipation power. Again, the comparison of the results of experiments and numerical simulations is presented.
The condition (3) contains only dissipation power corresponding to hydraulic power losses. However, the power curves (Figure 4) corresponding to the experiment include the mechanical losses as well.

The pump was tested on the closed test circuit, which is used for experimental testing of hydraulic turbines and low specific speed pumps. Circuit consists of the connecting pipes, pressurized vessel, which is connected to vacuum pump (for cavitation testing), the tested pump itself and feeding pump for the case of turbine testing. The tested pump is driven by dynamometer, which also measures pump torque and speed. Flow rate is measured using induction flowmeter, pressure difference between pump suction and delivery throats is assessed using pressure sensors. Measurement procedure and data evaluation is according to valid standard ČN EN ISO 9906.

Higher deviations of obtained experimental values are due to higher mechanical losses. They were caused by the action of axial forces on the impeller. The impellers with thick trailing edges were made from plastic using rapid prototyping method. A deformation of the plastic impeller occurred during the measurements that resulted in friction of the impeller against the pump cover. For this reason it was not possible to make a computation of hydraulic power and efficiency from their total values (Figure 5).

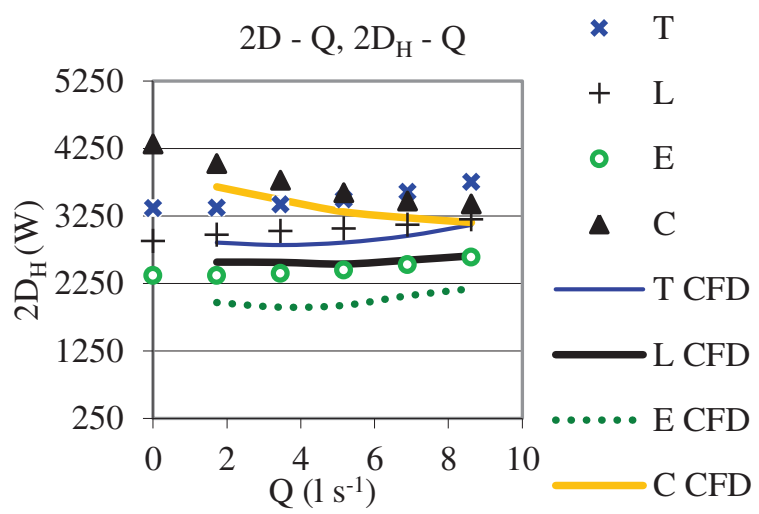

Figure 4. Dissipation power in the pump.

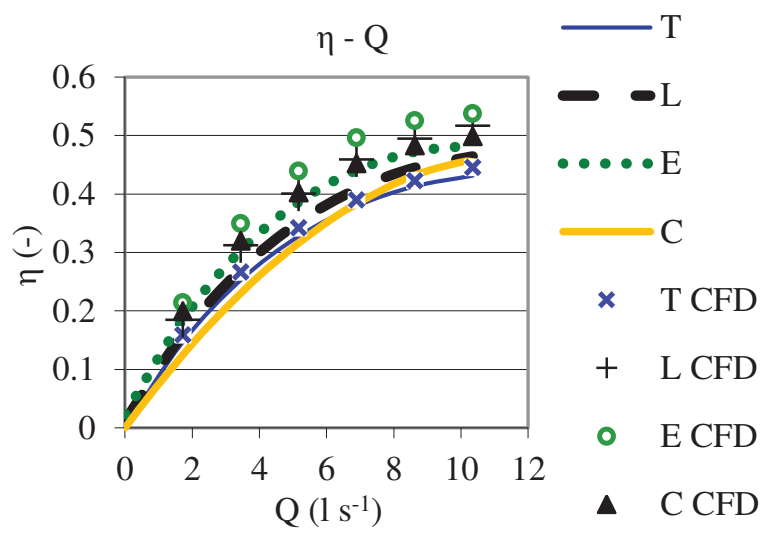

Figure 5. The curves of hydraulic efficiency (CFD) and total efficiency (experiment) in the pump. 


\section{Analysis of pump interior}

In this part of the analysis the pump was divided into the basic functional parts such as spiral case, blade channels and gaps between rotor and stator discs. Subsequently dissipation power was evaluated in every part. However, dissipation power corresponds only to the hydraulic losses according to condition (3). Main parts of pump are displayed in Figure 6.

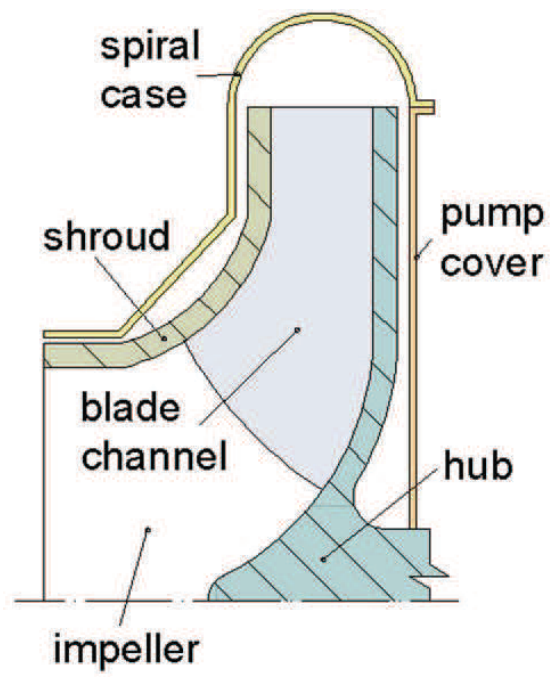

Figure 6. Meridional section of the pump.

First of all the dissipation power characteristics of spiral case will be presented (Figure 7). The main finding that we can observe on the base of this evaluation, is the fact that the flow in the spiral case caused by the impellers with thick trailing edges contribute to instability much more than in case of the conventional impellers C. From this point of view the worst are impellers with thick trailing edges and impellers with thick trailing edges and L-shaped recirculation channels. Figure 7 introduces the adjustments on the spiral case which will be studied in the future, e.g. [7]. The dissipation power in blade channels of impellers will be further analysed (Figure 8).

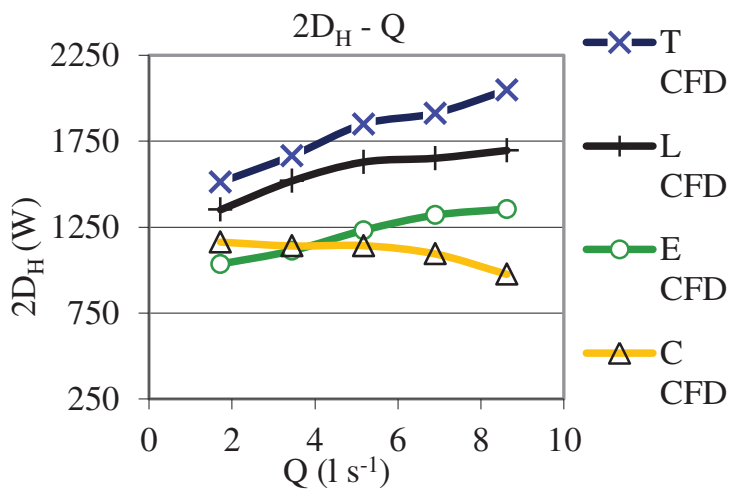

Figure 7. Dissipation power in the spiral case.

In terms of condition (3) a significant positive impact of blade channels of conventional impellers on stability of specific energy curves is evident. Besides, the reducing of the dissipation power magnitude it is also obvious that the blade channels of the impellers with thick trailing edges may only slightly contribute to the stability.

The remaining parts of pump that will be also analysed are the gap between the hub and the pump cover (stator disc) and between the shroud and the pump body.

For conventional impeller the gap had to be split into two parts as the hub is not full (in Figure 1 marked as C1, $\mathrm{C} 2$ ). The gap thus corresponds to the space between the two walls and the space between the fixed wall of the pump cover and the blade channels. Figure 9 shows that this gap has stabilizing effect with regard to the Y-Q characteristics for all types of impellers.

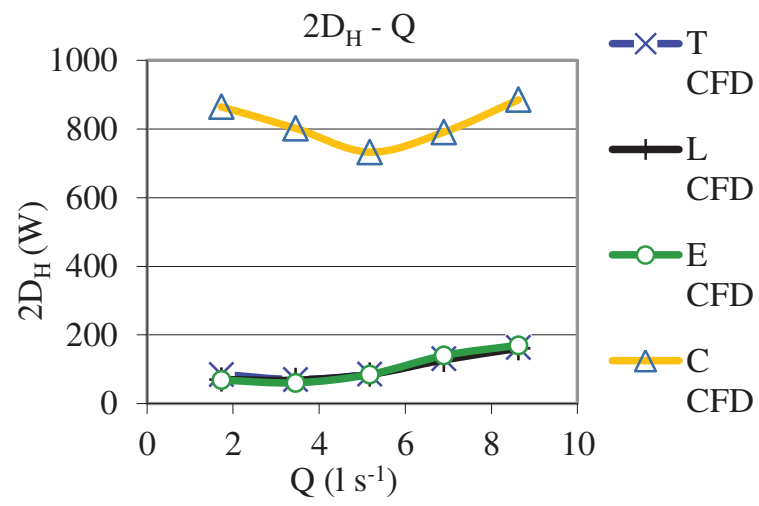

Figure 8. Dissipation power in blade channels.

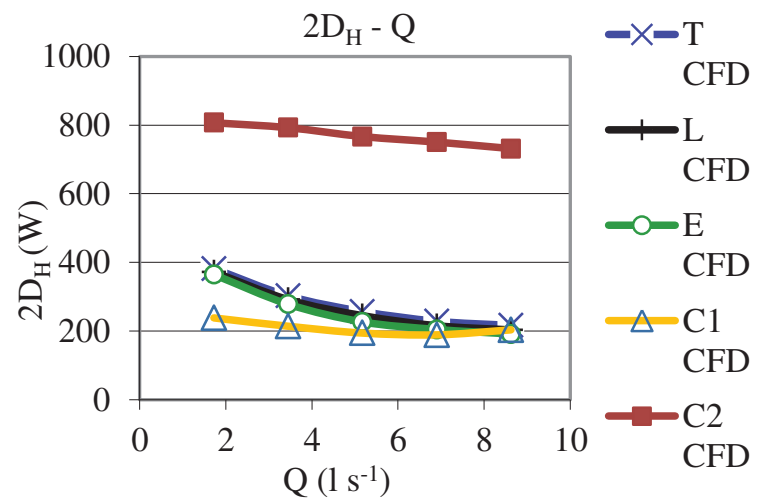

Figure 9. Dissipation power in the gap between the hub and cover of the pump.

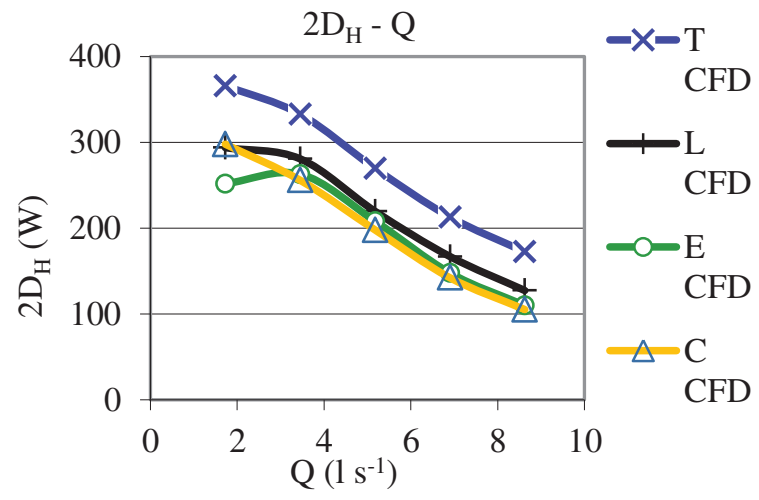

Figure 10. Dissipation power in the gap between the shroud and stator of the pump. 
The situation is different for the second gap between shroud and stator parts (Figure 10). The impellers with thick trailing edges without recirculation channels followed by L-shaped and T-shaped recirculation channels appear worst in this case. The best results are achieved again by conventional impeller with thin blades.

\section{Pressure pulsations within the pump}

Basic information about the size of impact on the static pressure amplitudes will be determined from the pressure pulsations in the interior of the whole centrifugal pump on the discharge and suction throats (Figure 11 and Figure 12). All statistics will be monitored close to the shut-off point and in the vicinity of the design point. The pressure amplitudes are plotted in dependence on the rotation of the impeller during the CFD simulation.

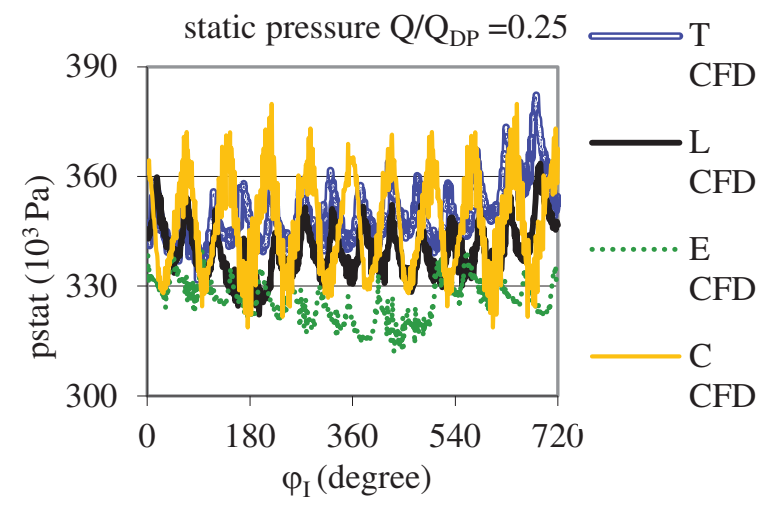

Figure 11. Static pressure pulsation in the whole pump interior close to the shut-off point.

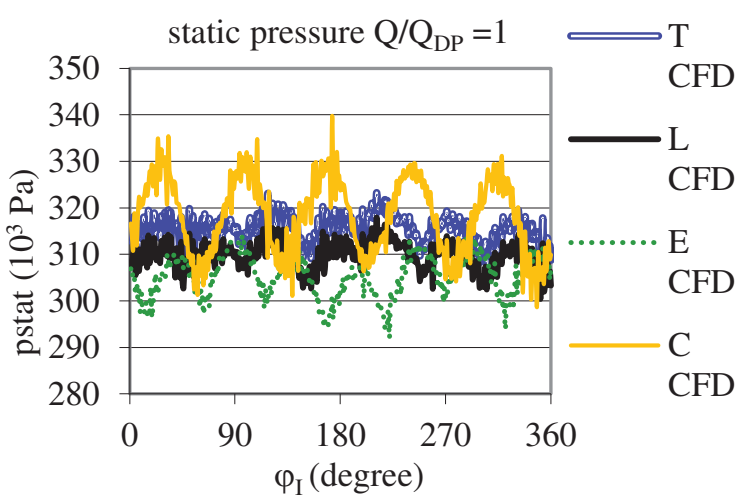

Figure 12. Static pressure pulsation in the whole pump interior close to the best efficiency point.

The worst results are reached by conventional impellers and impellers with $\mathrm{T}$-shaped recirculation channels close to the shut-off point. In the design point it is obvious that impellers with thick trailing edges and impellers with thick trailing edges and recirculation channels reduce the amplitude of the pressure pulsations in comparison with conventional impellers.

Filling of recirculation channels by liquid and their impact on the specific energy of the pump is very closely related to axial forces acting on the impeller [8, 9].
However, to compare magnitude of the axial forces reliably, it is necessary to achieve higher accuracies of CFD simulations for prediction of the recirculation channels function.

\section{Conclusions}

Based on the analysis of impellers with thick trailing edges and impellers with thick trailing edges and with recirculation channels following conclusions can be drawn:

T-shaped recirculation channels contribute to the stability of specific energy curves. T-shaped channels also reach the highest values of specific energy. However, the disadvantage is lower value of the hydraulic efficiency. On the contrary, L-shaped recirculation channels cause slight instability of specific energy curves. However, their advantage is the best hydraulic efficiency. The analysis of the energy dissipation in the centrifugal pump interior shows that the spiral body is one of the major contributors to instability of the impellers with thick trailing edges. Also the gap between the hub and the pump cover (stator disc) negatively affects the stability of specific energy curves. The best situation, from this point of view, is for $\mathrm{T}$ shaped recirculation channels in the case of the impellers with thick trailing edges and with recirculation channels. The worst results are achieved by common impeller with thick trailing edges.

Regarding the pressure pulsations, it appears that recirculation channels may reduce the amplitude of these pulsations in the design point in comparison with the impeller with thick trailing edges without recirculation channels. On the other hand, close to the shut-off point the pressure pulsations are lowest for the impellers with thick trailing edges and without recirculation channels. This fact is related to the size of the total area, through which the liquid flows from the impeller into the spiral case. Similar results are obtained in terms of pressure pulsations in the spiral case.

\section{References}

1. J.F. Gülich, Centrifugal Pumps (Heidelberg Springer-Verlag, 2010)

2. C. E. Brennen, Hydrodynamics of Pumps (New York: Oxford University Press, 1994)

3. Y. Meng, Ch. Li, H. Yan, X. Liu, Proc. Int. Conf. on Computer Eng. and Aplications (Manila), 2, pp 179183 (2009)

4. J. F. Gülich, U. Bolleter, ASME J Vib Acoust, 114, 272-9 (1992)

5. F. Pochylý, M. Haluza, S. Drábková, Engineering Mechanics 2009 - book of extended abstract, 208215 (2009)

6. H. Benigni, H. Jaberg, H. Yeung, J. Fluids Eng. 134 024501-4 (2012)

7. Y. W. Wong, W. K. Chan, W. Hu, Artificial Organs, 31(8), 639-645 (2007)

8. G. Schaefer, E. Olson, Journal of World Pumps Issue 393 pp 34-37 (1999) 
9. V. Godbole, R. Patil, S. Gavade, 15th Int. Conf. Experimental Mechanics (Porto) Paper ref: 2977 pp $1-14$ (2012)

\section{Acknowledgement}

Project CZ.1.07/2.3.00/30.0005 "Podpora tvorby excelentních týmů mezioborového výzkumu na VUT" is gratefully acknowledged for support of this research. 